\title{
A ENHANCE PLL STRATEGY FOR DISTRIBUTION GRID INTEGRATED TO PHOTOVOLTAIC SYSTEM FOR POWER QUALITY ENHANCEMENT
}

\author{
Yashashri B. Deshmukh ${ }^{1}$, S. P. Adhau ${ }^{2}$, P. G. Adhau ${ }^{3}$, X. R. Pote ${ }^{4}$ and V.S. Rajguru \\ 'PG Scholar, ${ }^{2,3,5}$ Associate Professor and ${ }^{4}$ Assistant Professor \\ ${ }^{1,2,4}$ Dept of Electrical Engineering, Yeshwantrao Chavan Colege of Engineering Nagpur, India \\ ${ }^{3}$ Department of Electrical Engineering, Shri Datta Meghe Polytechnic, Nagpur, India \\ ${ }^{5}$ Department of Electrical Engineering, Govt. college of Engieering, Aurangabad, India
}

\begin{abstract}
Distribution grid integrated to photovoltaic system is gaining more attention now-a-days. The photovoltaic system can provide active power to the load and grid at reduced cost. In this paper, photovoltaic energy conversion system is used for providing power to the load and grid. Perturb and observe method is utilize to track maximum power under varying irradiance condition to provide constant active power. The detection and extraction of accurate phase angle under unbalance utility condition is achieved by using three phase magnitude PLL. The solar power is transfer to the load during day time and voltage source inverter act as a shunt active power filter at night which minimizes the burden of active power filter. The modelling and simulation of system is carried out in MATLAB software to reveal its usefulness.
\end{abstract}

Key Words : Three Phase-Magnitude phase lock loop (PLL), photovoltaic energy conversion system.

\section{Introduction}

In urban area, power generation from photovoltaic system is proving major tactics and utilization of PV panels on rooftops of building in commercial and industrial area are increasing[1]. Due to the advantages of photovoltaic system such as it provide clean energy at minimum cost. Thus, it is gaining more attention.

As the demand for power is increasing from few decades, it become necessary to increase power generation to meet the power demand. In such condition, utilization of fossil fuels results in emission of greenhouse gases. The use of photovoltaic system overcomes the drawback of fossil fuels. The varying irradiance and varying temperature in photovoltaic system affects the power generation and minimizes the efficiency. In order to track maximum power different maximum power tracking techniques are proposed. In this paper, perturb and observe method is used to track maximum power under varying irradiance condition. The function of photovoltaic system is to transfer constant active power with the help of dc-dc converter.

The accurate synchronization of grid-integrated power converter with utility is important to be consider. The extraction of positive sequence component from voltage at fundamental frequency is necessary for UPS, FACT systems [5], power line conditioners. As we know that non-linear loads introduces harmonics in grid current which affects performance of control and protection devices and may cause unbalances. Thus, it is essential to design a control which is able to filter out the noise and distortion in order to enhance power quality.

Commonly PLL is used for synchronization. Various PLL topologies are given in literature from which zero crossing detection method is the easiest one [6]. The main drawback of these method is its sensitivity. These paper gives a possible choice for the detection of phase and amplitude of positive sequence component for unbalance condition, that is to say 3ph-M PLL.

The proposed control i.e. 3ph-M PLL is utilize to detect and estimate accurate phase angle by extracting positive sequence voltage from applied three phase voltage and attenuate negative sequence and zero sequence component. As compared to conventional PLL, 3ph-M PLL is robust and utilizes linear feedback loop and mitigated the unbalance under unsymmetrical utility condition.

As the grid connected is close loop system, switching for voltage source inverter is done by using current controller. In this paper, hysteresis current controller is utilize with unit templates which generate necessary signal for switching of inverter. Hysteresis current controller consist of two bands i.e. upper band and lower band. The actual current is compared with reference current in order to produce error. If this error current reaches upper hysteresis band, lower switches turn ON and if the error current reaches lower hysteresis band, upper switches turn ON. 


\section{Configuration of Grid Connected Photovoltaic System}

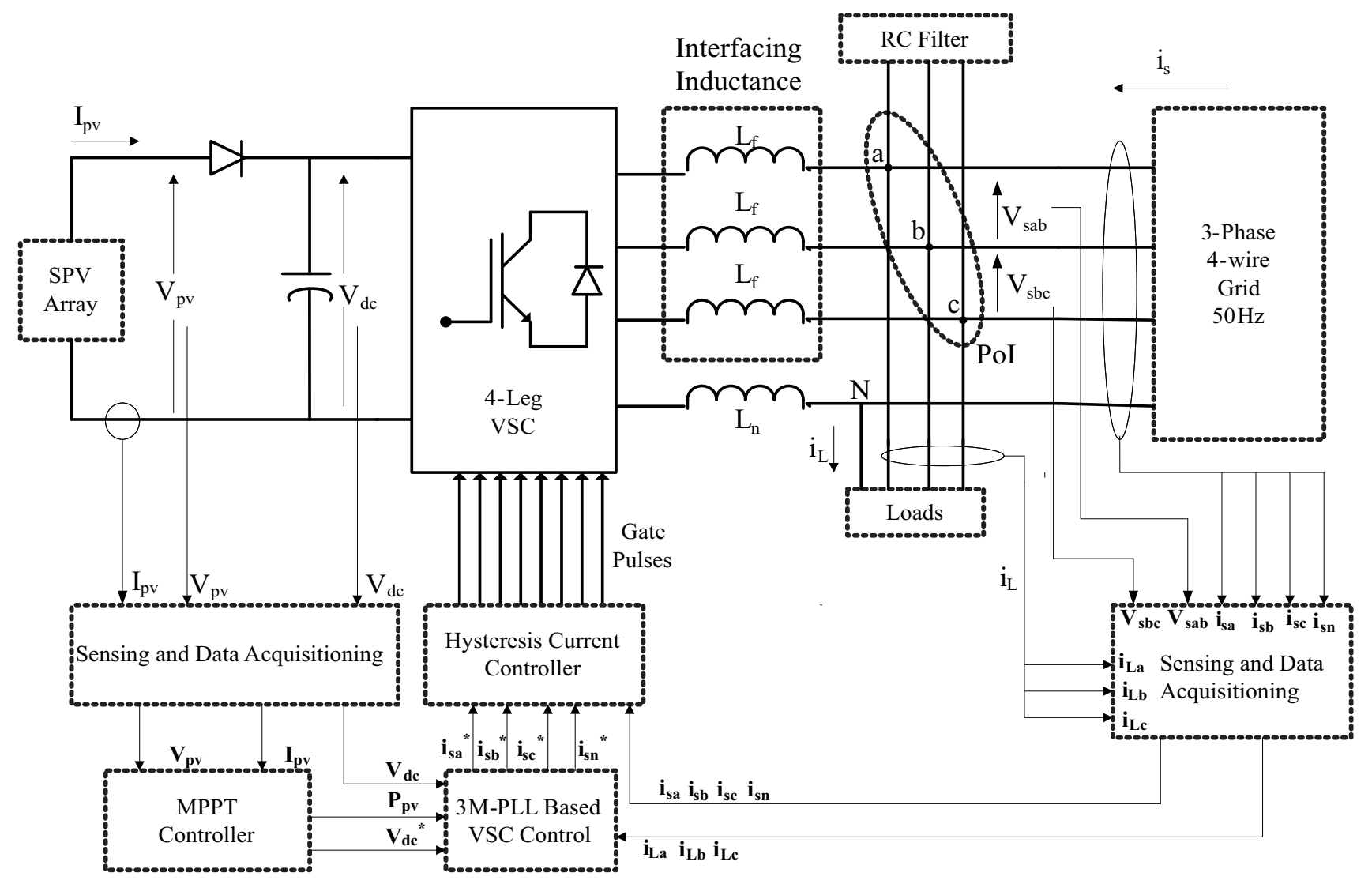

Fig.1 : Structure of grid connected photovoltaic system

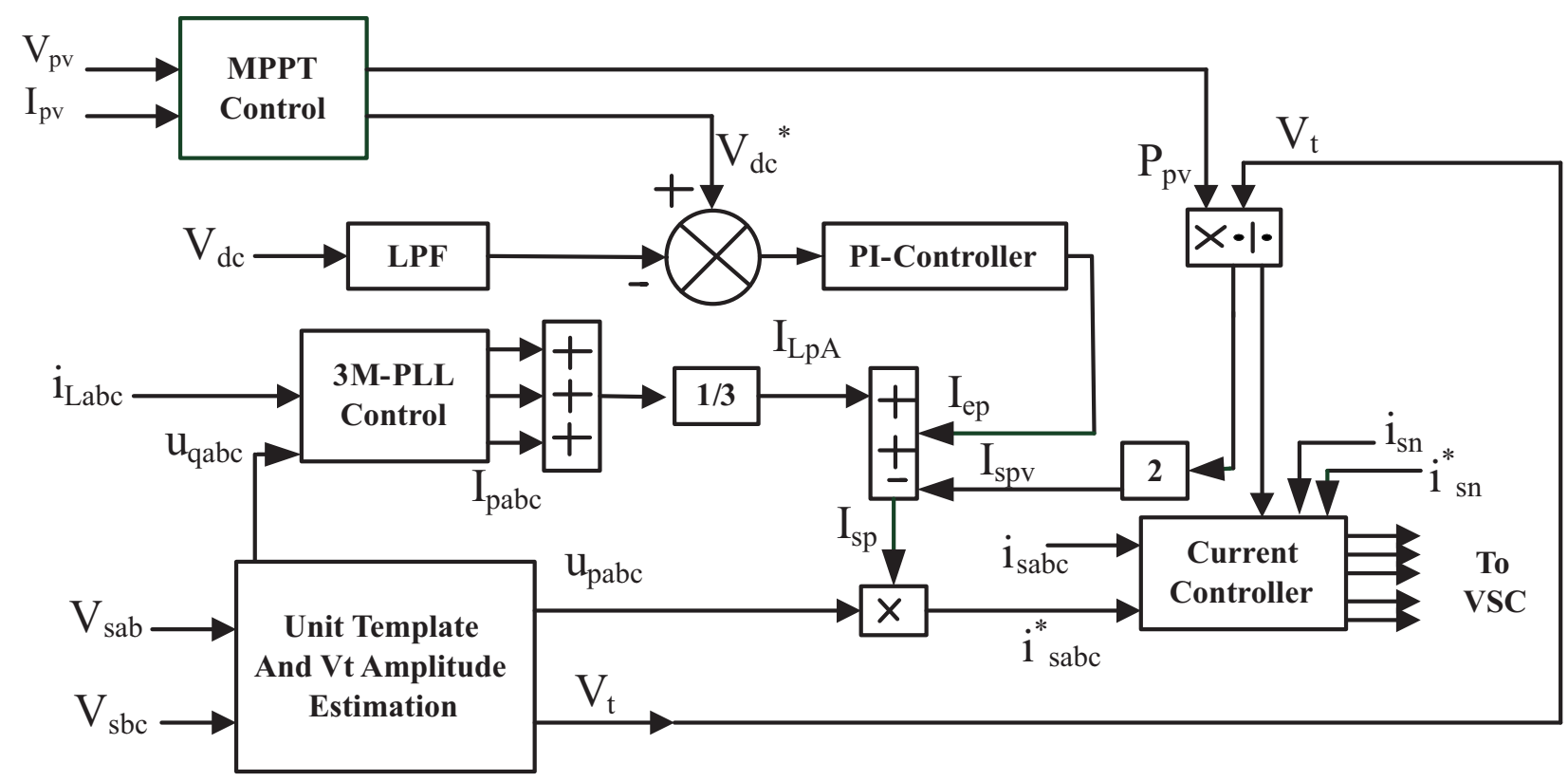

Fig. 2 : Control scheme for grid connected photovoltaic system 
The block diagram of experimental paradigm of $3 \mathrm{Ph}-4 \mathrm{~W}$ grid integrated PvECS is given in Fig (1). The model consist of PV array, three phase VSI, DC link capacitor (Vdc) between PV and VSI, 3Ph-4W grid with impedance (Zs), interfacing inductance (Lf), ripple filter, three phase load. The use of ripple filter is to filter out the high switching noise which are cause due to VSI. The interfacing inductance is utilize in order to mitigate the ripples the inverter current.

The control scheme of PvECS integrated to 3Ph- $4 \mathrm{~W}$ grid is shown in Fig (2). In order to enhanced the efficiency and reduce losses due to number of component single stage PvECS is utilize. Conventional solar system only provide active power to the load and grid. The PvECS can fulfil the need of active power for single phase and three phase load simultaneously. The control scheme for PvECS integrated to distribution grid is divided into two controls, in which one is perturb and observe based MPPT control for tracking the maximum power under varying irradiance and temperature condition. Second is PLL with 3ph-M PLL. SPWM modulation technique is utilized for producing switching pulses for three phase VSI.

\section{A. MPPT control}

As the solar irradiance and temperature varies point to point, it become necessary to track maximum power in order to give constant supply to the load and grid during day time. There are various MPPT techniques which are explain in articles $[4,5]$. Among all of these techniques, perturb and observe method is used to track the maximum power. The objective of this block is to calculate PV power (Ppv) and reference DC link voltage ( $\left.\mathrm{Vdc}^{*}\right)$.

\section{B. Proposed 3ph-M PLL}

The proposed PLL, is shown in Fig.4. It is nothing but the extension of conventional PLL. Consider a signal)(tu.

$$
u(t)=u_{0}(t)+d(t)+n(t)
$$

where,

$$
u_{0}(t)=\left(\begin{array}{l}
u_{a 0}(t) \\
u_{b 0}(t) \\
u_{c 0}(t)
\end{array}\right)=\left(\begin{array}{l}
V_{0} \sin \left(\omega_{0} t+\delta_{0}\right) \\
V_{0} \sin \left(\omega_{0} t+\delta_{0}-\frac{2 \Pi}{3}\right) \\
V_{0} \sin \left(\omega_{0} t+\delta_{0}+\frac{2 \Pi}{3}\right)
\end{array}\right)
$$

In expression ( 1$), d(t)$ and $n(t)$ is a unwanted part of signal and extraction of fundamental signal is the main function.

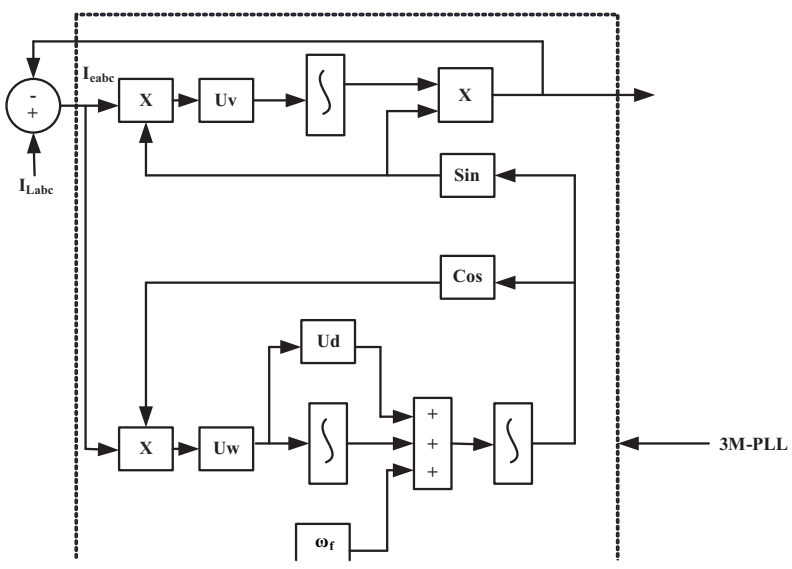

Fig. 3 : 3ph-M PLL

The constants i.e. uv, ud, and uw affects system operation as uv controls system settling time and amplitude of response and slow or oscillatory response are made by ud and uw. [6]

\section{A. Computation of unit template}

The phase voltages are obtained from the equations [7],

$$
\begin{gathered}
v_{s a}=\frac{2 v_{s a b}+v_{s b c}}{3} \\
v_{s b}=\frac{-v_{s a b}+v_{s b c}}{3} \\
v_{s c}=\frac{-v_{s a b}-2 v_{s b c}}{3}
\end{gathered}
$$

The peak magnitude of terminal voltage (Vt ) is computed as,

$$
V_{t}=\sqrt{\frac{2}{3}\left(v_{s a}^{2}+v_{s b}^{2}+v_{s c}^{2}\right)}
$$

The in-phase unit templates are estimated as,

$$
u_{p a}=\frac{v_{s a}}{V_{t}} \quad u_{p b}=\frac{v_{s b}}{V_{t}} \quad u_{p c}=\frac{v_{s c}}{V_{t}}
$$

The quadrature unit templates are estimated as,

$$
\begin{aligned}
& u_{q a}=-\frac{u_{p b}}{\sqrt{3}}+\frac{u_{p c}}{\sqrt{3}} \quad u_{q b}=\frac{\sqrt{3} u_{p a}}{2}+\frac{\left(u_{p b-} u_{p c}\right)}{2 \sqrt{3}} \\
& u_{q c}=-\frac{\sqrt{3} u_{p a}}{2}+\frac{\left(u_{p b-} u_{p c}\right)}{2 \sqrt{3}}
\end{aligned}
$$




\section{Interpretation of reference current}

The total in-phase term can be obtain as,

$I_{s p}=I_{L p A}+I_{c p}-I_{s p v}$

Where, $I_{L p A}$ is average amplitude of in-phase load component detected for load balancing as,

$I_{L p A}=\frac{\left(I_{p a}+I_{p b}+I_{p c}\right)}{3}$

The actual current is compared with reference current and eight switching pulses are generated for VSI [8].

\section{Simulation Parameters}

Table 1

System Parameters

\begin{tabular}{|l|l|}
\hline \multicolumn{1}{|c|}{ Name } & Simulated values \\
\hline Open circuit voltage (Voc) V & $32.9 \mathrm{~V}$ \\
\hline Short circuit current (Isc) A & $9.88 \mathrm{~A}$ \\
\hline Number of panel in series (Ns) & 22 \\
\hline Number of panel in parallel (Np) & 4 \\
\hline PV array power P $\mathrm{PV}_{\mathrm{PV}}$ and current, $\mathrm{I}_{\mathrm{PV}}$ & $715 \mathrm{~V}, 40.6 \mathrm{~A}$ \\
\hline PV voltage, $\mathrm{V}_{\mathrm{P}}$ & $2.5 \mathrm{mh}$ \\
\hline interfacing inductor, Lf & $230 \mathrm{~V}(\mathrm{rms})$ \\
\hline grid voltage, vab & $669 \mathrm{~V}$ \\
\hline DC bus voltage, Vdc & $1 \mu \mathrm{s}$ \\
\hline sampling time, Ts & $\begin{array}{l}\mathrm{R}=10 ? \text { and } \\
\mathrm{L}=100 \mathrm{mH}\end{array}$ \\
\hline Non-linear load & \\
\hline
\end{tabular}

\section{Simulation Results}

In order to verify control scheme design for $3 \mathrm{Ph}-4 \mathrm{~W}$ grid connected photovoltaic system, simulation has been done on MATLAB. The network is subjected various conditions such as unbalance or changing irradiance. The system parameters are mention in table I.

\section{A. Operation subjected to varying solar irradiance}

The PV panel is modelled in MATLAB software where, 22 panels are connected in series and 4 panels are connected in parallel. Fig (3) shows simple P-V and I-V characteristic of PV panel. The irradiance is varied for 850
$\mathrm{W} / \mathrm{m} 2,1300 \mathrm{~W} / \mathrm{m} 2$ and $600 \mathrm{~W} / \mathrm{m} 2$ as shown in fig (4) and corresponding P-V and I-V curve is shown in fig (5). Under varying irradiance condition, perturb and observe technique is implemented with the help of dc-dc converter. The output of converter after applying MPPT method is shown in Fig (6).
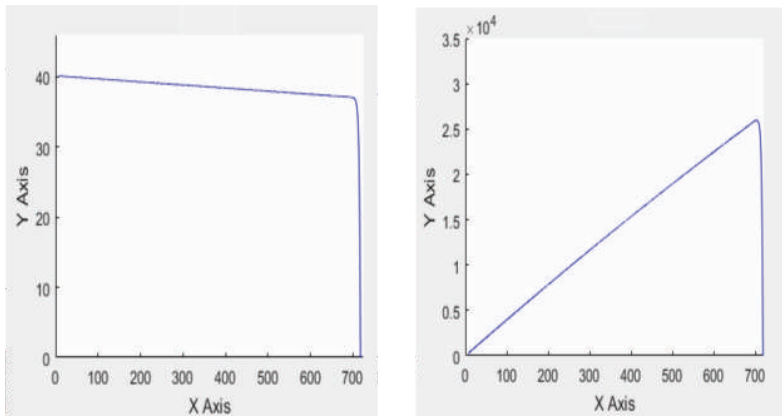

Fig. 3 : I-V and P-V characteristics

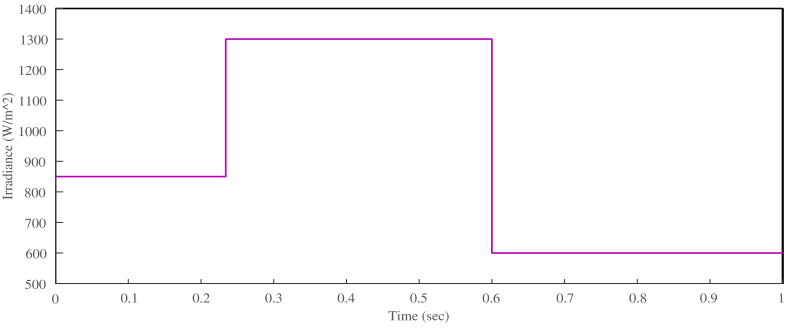

Fig. 4 : Irradiance level
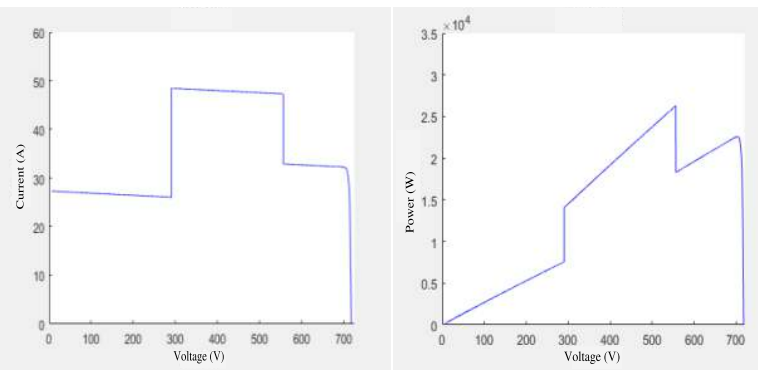

Fig. 5 : I-V and P-V characteristics
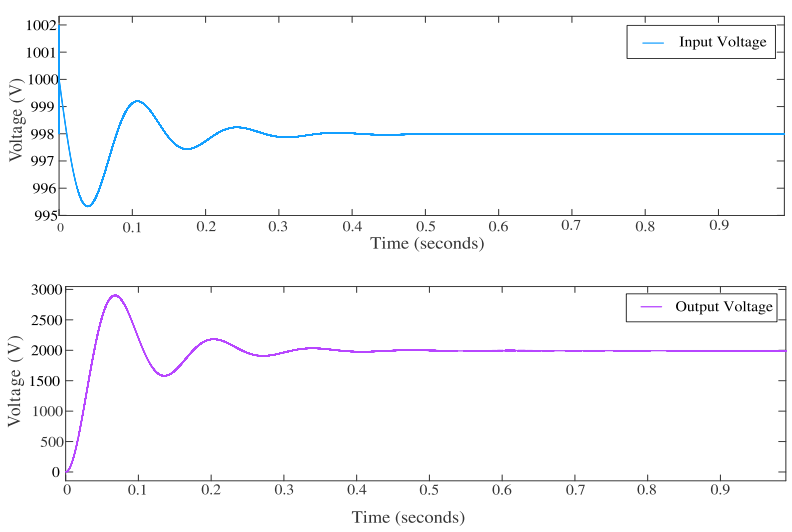

Fig. 6 (a) : Input-output voltage waveform of boost converter 

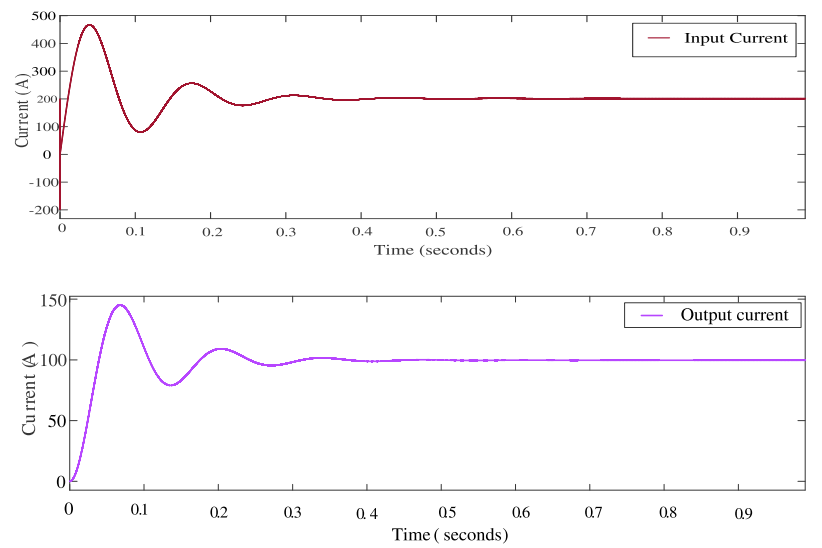

Fig.6 (b) : Input-output current waveform of boost converter

\section{B. Operation under unbalance condition}

Fig. 7 and 8 shows the results under unbalance condition where load voltage and current is shown in Fig.7 (a) and (b) and grid voltage and current is shown in Fig.8 (a) and (b). The unbalance is made by disconnecting phase $\mathrm{c}$ for a time period of 0.002 to $0.1 \mathrm{sec}$ on load side. The function of control is to maintain grid current balance. The grid neutral current is maintain almost zero in order to provide neutral current compensation. It also reduces the THD from $37.4 \%$ to $1.21 \%$ given in table II.

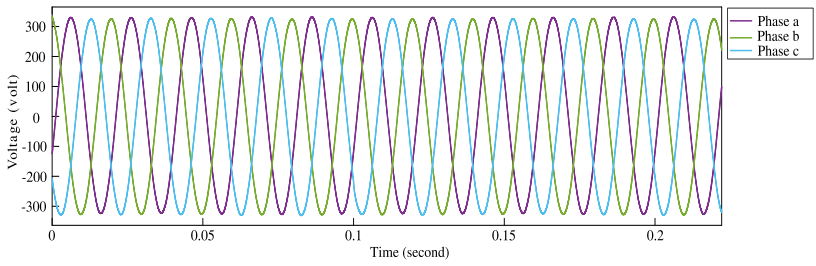

Fig. 7 (a) : Load voltage
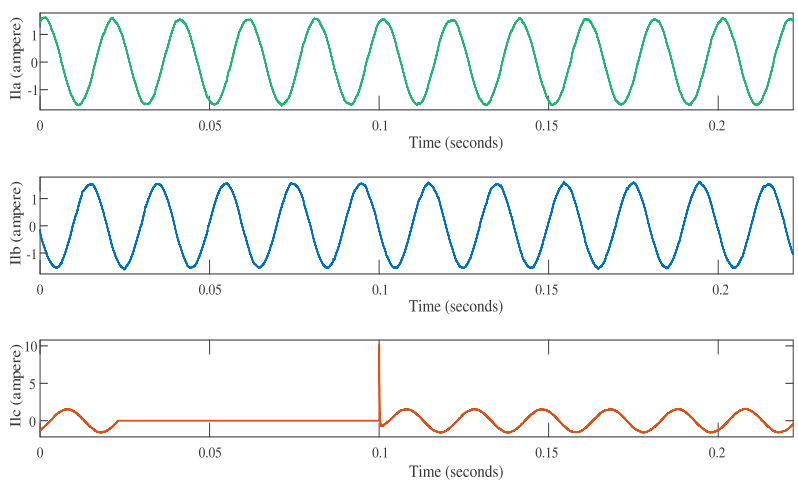

Fig. 7 (b) : Load current
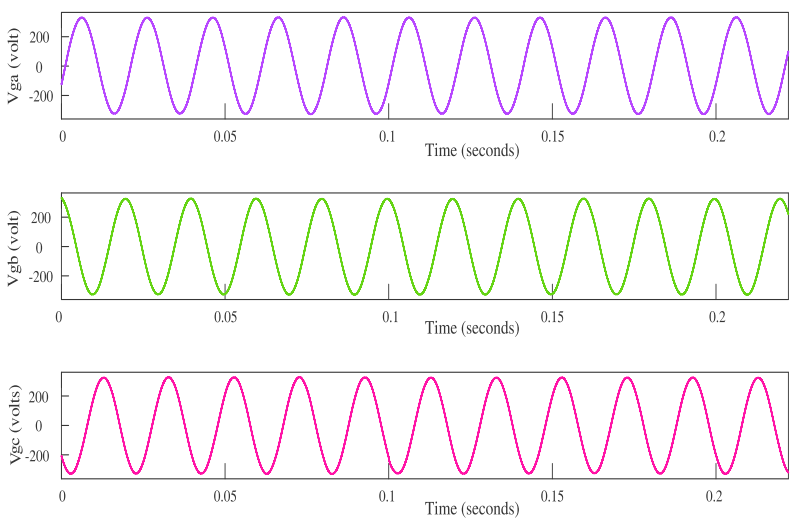

Fig.8 (a) : Grid voltage
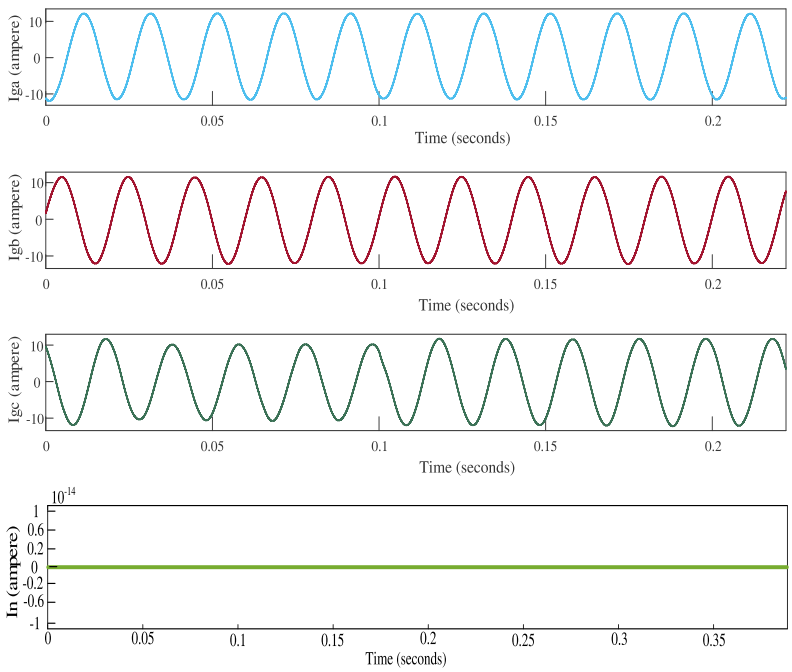

Fig.8 (b) : Grid current

\begin{tabular}{|lcc|}
\hline & $\begin{array}{c}\text { TABLE II } \\
\text { Load Current }\end{array}$ & Grid Current \\
Phase & (THD \%) & (THD \%) \\
\hline & 2.84 & 2.30 \\
Phase a & 3.02 & 2.55 \\
Phase b & 2.00 & 1.21 \\
\hline Phase c & & \\
\hline
\end{tabular}




\section{Conclusion}

The $3 \mathrm{Ph}-4 \mathrm{~W}$ grid connected to photovoltaic system is proposed in this paper. The photovoltaic system provide active power to load and grid. The 3ph-M PLL is utilized for maintaining balance condition on grid side in case of unbalance occurred due to fault on load side and to mitigate the harmonic distortion occurred due to nonlinear load. This control maintains balance current and voltage on grid side and inverter side under unbalance condition on utility side. It also reduces THD below a limit i.e. less than $5 \%$. Also the power factor is maintained to unity

\section{References}

[1] Muro, M., Saha, D.: 'Why rooftop solar - and full retail feed in tariffs - benefits all consumers', 30 May 2016 . Available at http:// reneweconomy.com.au/2016/rooftop-solar-netmetering-is-a-netbenefit-28170.

[2] P. Rodríguez, J. Bergas, and J. A. Gallardo, “A new positive sequence voltage detector for unbalanced power systems," in Proc. Eur. Conf. Power Electron. Appl., Sep. 2002, [CD ROM].

[3] P. Rodriguez, L. Sainz, and J. Bergas, "Synchronous double reference frame PLL applied to a unified power quality conditioner," in Proc. IEEE Int. Conf. Harm. Power Quality, Oct. 2002, vol. 2, pp. 614-619.

[4] Kish, G.J., Lee, J.J., Lehn, P.W.: 'Modelling and control of photovoltaic panels utilising the incremental conductance method for maximum power point tracking', IET Renew. Power Gener., 2012, 6, (4), pp. 259-266.
[5] Sekhar, P.C., Mishra, S.: 'Takagi-sugeno fuzzybased incremental conductance algorithm for maximum power point tracking of a photovoltaic generating system', IET Renew. Power Gener., 2014, 8, (8), pp. 900-914.

[6] Karimi-Ghartemani, M.: 'A novel three-phase magnitude-phase-locked loop system', IEEE Trans. Circuits Syst. I, Regular Papers, 2006, 53, (8), pp. 1792-1802

[7] Akagi, H., Watanabe, E.H., Aredes, M.: 'Instantaneous power theory and applications to power conditioning' (Wiley-IEEE Press, Hoboken, NJ, 2007) [28] IEEE Recommended Practices and requirement for Harmonic Control on Electric Power System, IEEE Std.519, 1992.

[8] Agarwal, R., Hussain, I., Singh, B.: 'LMF based control algorithm for single stage three-phase grid integrated solar PV system', IEEE Trans. Sust. Energy, 2016, 7, (4), pp. 1379-1387. 